\title{
Correlation of COX-2 and Ep-CAM overexpression in human invasive breast cancer and its impact on survival
}

\author{
G Spizzo', G Gastl', D Wolf', E Gunsilius', M Steurer', D Fong ${ }^{2}$, A Amberger ${ }^{3}$, R Margreiter ${ }^{3}$ and P Obrist*,2 \\ 'Division of Haematology \& Oncology, University of Innsbruck, A-6020 Innsbruck, Austria; ${ }^{2}$ Department of Pathology, University of Innsbruck, A-6020 \\ Innsbruck, Austria; ${ }^{3}$ Tyrolean Cancer Research Institute, University of Innsbruck, A-6020 Innsbruck, Austria
}

Recent studies have demonstrated cyclooxygenase 2 (COX-2) overexpression in various human malignancies, especially in breast cancer, where COX-2 turned out to be a predictor of poor survival. To evaluate the relation of COX-2 and Ep-CAM overexpression and its prognostic significance, we performed a retrospective study on 212 breast cancer patients with a median follow-up time of 10.5 years. Overexpression of COX-2 in tumour tissue samples was assessed by immunohistochemistry. COX-2 overexpression was found in $48.6 \%$ of the tumour samples and was predictive for poor disease-free and overall survival. Univariate analysis revealed a strong correlation between COX-2 and Ep-CAM overexpression $(P=0.009)$. Concurrent COX-2 and Ep-CAM overexpression was present in $21.7 \%$ of tumour specimens and had an additive negative impact on disease-free and overall survival. Determination of both tumour markers should help in guiding new therapeutic strategies in patients with invasive breast cancer.

British Journal of Cancer (2003) 88, 574-578. doi:I0.1038/sj.bjc.660074I www.bjcancer.com

(C) 2003 Cancer Research UK

Keywords: breast cancer; prognosis; COX-2; Ep-CAM

Cyclooxygenase-2 (COX-2) is a prostaglandin synthase that catalyses the synthesis of prostaglandin $\mathrm{G}_{2}\left(\mathrm{PGG}_{2}\right)$ and $\mathrm{PGH}_{2}$ from arachidonic acid. Recent studies have led to the recognition of the importance of COX-2 in tumorigenesis of different tumour types. It has been shown that COX-2 is involved in tumour angiogenesis (Tsujii et al, 1998; Gately, 2000), in suppression of apoptosis (Sheng et al, 1998) and in the promotion of invasiveness (Tsujii et al, 1997). COX-2 overexpression was found in pancreatic (Molina et al, 1999; Okami et al, 1999; Kokawa et al, 2001), oesophageal (Zimmermann et al, 1999), prostate (Yoshimura et al, 2000), lung (Khuri et al, 2001), head and neck cancers (Chan et al, 1999) and in malignant gliomas (Shono et al, 2001). Tsujii et al reported that COX-2 overexpression in intestinal epithelial cells leads to downregulation of adhesion molecules (i.e. cadherins), resulting in an enhanced tumorigenic potential (Tsujii and DuBois, 1995).

Enhanced COX-2 expression in breast cancer was first indicated by reports of elevated prostaglandin levels in breast carcinomas (Bennett et al, 1977), particularly in patients with metastatic disease (Rolland et al, 1980). A key role of COX-2 for the initiation and progression of breast cancer is suggested by the finding that mere overexpression of COX-2 can be sufficient for inducing mammary gland tumorigenesis in transgenic mice (Liu et al, 2001). Notably, in human breast cancer cell lines, a positive correlation was found between invasiveness, metastatic potential and prostaglandin production (Liu and Rose, 1996). Different groups have

*Correspondence: Dr P Obrist, Department of Pathology, Innsbruck University Hospital, Müllerstrasse, 44, A-6020 Innsbruck, Austria; E-mail: Peter.Obrist@uibk.ac.at

Received I 5 July 2002; revised 21 October 2002; accepted 6 November 2002 described the prognostic significance of COX-2 overexpression in breast cancer (Hwang et al, 1998; Ristimaki et al, 2002; Soslow et al, 2000).

We have recently described the prognostic significance of EpCAM overexpression in patients with invasive breast cancer (Gastl et al, 2000). Ep-CAM (also called 17-1A, ESA, EGP40, 323/A3) is a $40-\mathrm{kDa}$ transmembrane glycoprotein expressed on most human epithelial cells (Gottlinger et al, 1986). The Ep-CAM glycoprotein functions as a homotypic intercellular adhesion molecule (Litvinov et al, 1994) and has become a target for antibody-mediated immunotherapy with the murine monoclonal antibody edrecolomab (Riethmuller et al, 1998). So far, no data have been reported on the correlation of COX-2 overexpression with Ep-CAM overexpression in human breast cancer. We therefore examined COX-2 and Ep-CAM overexpression in tumour specimens from 212 patients with invasive breast cancer, and analysed the prognostic value of both tumour markers.

\section{PATIENTS AND METHODS}

\section{Patient selection}

A total number of 212 patients were included in this retrospective analysis. This patient sample represents one-third of all cases with localised invasive breast cancer who were operated at the Department of Surgery, Innsbruck University Hospital, from 1980 to 1992. In fact, all cases for which paraffin-embedded tissue samples were still retrievable from the local pathology repository and for which clinical follow-up data were available, were included. Only patients without evidence of distant metastasis at the time of primary surgery and with well-documented axillary lymph node status were eligible for this analysis. The median age of the patients 
was 54.2 years (range, 29-85 years). Patients younger than 50 years were considered premenopausal. Of the women, $112(52.8 \%)$ were node-positive and $100(47.2 \%)$ node-negative. After primary surgery the clinical status was documented by re-evaluating each patient at least once annually at the Department of Surgery. The evaluation procedure included physical examination, mammography, abdominal ultrasound and chest radiography. The median follow-up time was 10.5 years (range, 36-240 months). During this observation period 96 patients relapsed. Of a total of 94 deaths, 84 were due to breast cancer, while 10 patients died without documented disease recurrence.

\section{Histopathology}

All tumour samples were formalin-fixed, embedded in paraffin wax and stored at the local pathology repository. Haematoxylinand eosin-stained slides were prepared from each tumour specimen using routine methods and then examined by light microscopy. Histologic type and tumour grade were assessed by one co-author (PO) in a blinded fashion using standard pathology criteria.

\section{Immunohistochemistry}

COX-2 overexpression was determined by immunohistochemistry using the murine monoclonal antibody COX-2 (Cayman, USA). Briefly, $5-\mu \mathrm{m}$ sections were cut from paraffin-embedded tissue blocks, mounted on adhesive-coated glass slides, deparaffinised and rehydrated. Endogenous peroxidase was inactivated by immersing the slides in $0.3 \% \mathrm{H}_{2} \mathrm{O}_{2}$ in absolute methanol for $20 \mathrm{~min}$ at room temperature. Pretreatment consisted of a 15-min incubation period in a water bath at $90^{\circ} \mathrm{C}$. After washing in Tris buffer, slides were incubated for $2 \mathrm{~h}$ with the primary antibody (COX-2, Cayman, USA, dilution $1: 100$ ). Afterwards, a peroxidaseconjugated goat anti-mouse antibody ready-to-use $\left(\right.$ EnVision $^{\mathrm{TM}}$,
DAKO, Vienna, Austria) was added for $30 \mathrm{~min}$. For immunostaining, slides were then placed into the chromogen consisting of a diaminobenzidine solution. Finally, slides were counterstained with Mayer's Hemalum solution. In addition, slides were immunostained for Ep-CAM essentially as described previously (Gastl et al, 2000; Spizzo et al, 2002).

\section{Evaluation of slides}

COX-2 overexpression was evaluated by two independent assessors (GS and PO) using light microscopy. Reading of tissue slides was blinded, and both assessors were unaware of clinical outcome. COX-2 expression was defined as the presence of specific staining in the cytoplasm of tumour cells. A final expression score was calculated for each tissue sample by multiplying a staining intensity score ( 0 , negative; 1 , weak; 2 , moderate; 3 , strong staining) with a proportion score of positively stained cells $(1,1-10 \% ; 2,11-50 \% ; 3,50-80 \% ; 4,80-100 \%)$. Only samples with a final expression score $>4$ were defined as 'overexpressing'. Ep-CAM overexpression was evaluated as previously reported (Gastl et al, 2000; Spizzo et al, 2002).

\section{Statistical methods}

Statistical analysis was performed with the SPSS software program for Windows ${ }^{\mathrm{TM}}$. The primary end points in this study were diseasefree and overall survival. Thus, survival curves were calculated according to the method of Kaplan and Meier. $P$-values were evaluated using the log-rank test for censored survival data. Follow-up time was censored if the patient was lost to follow-up. Patients who died without documented disease recurrence were considered censored for disease-free survival but were included as deaths for overall survival analysis. The relation between antigen overexpression and other clinical or tumour parameters was calculated with the $\chi^{2}$ test. To determine the relative importance of
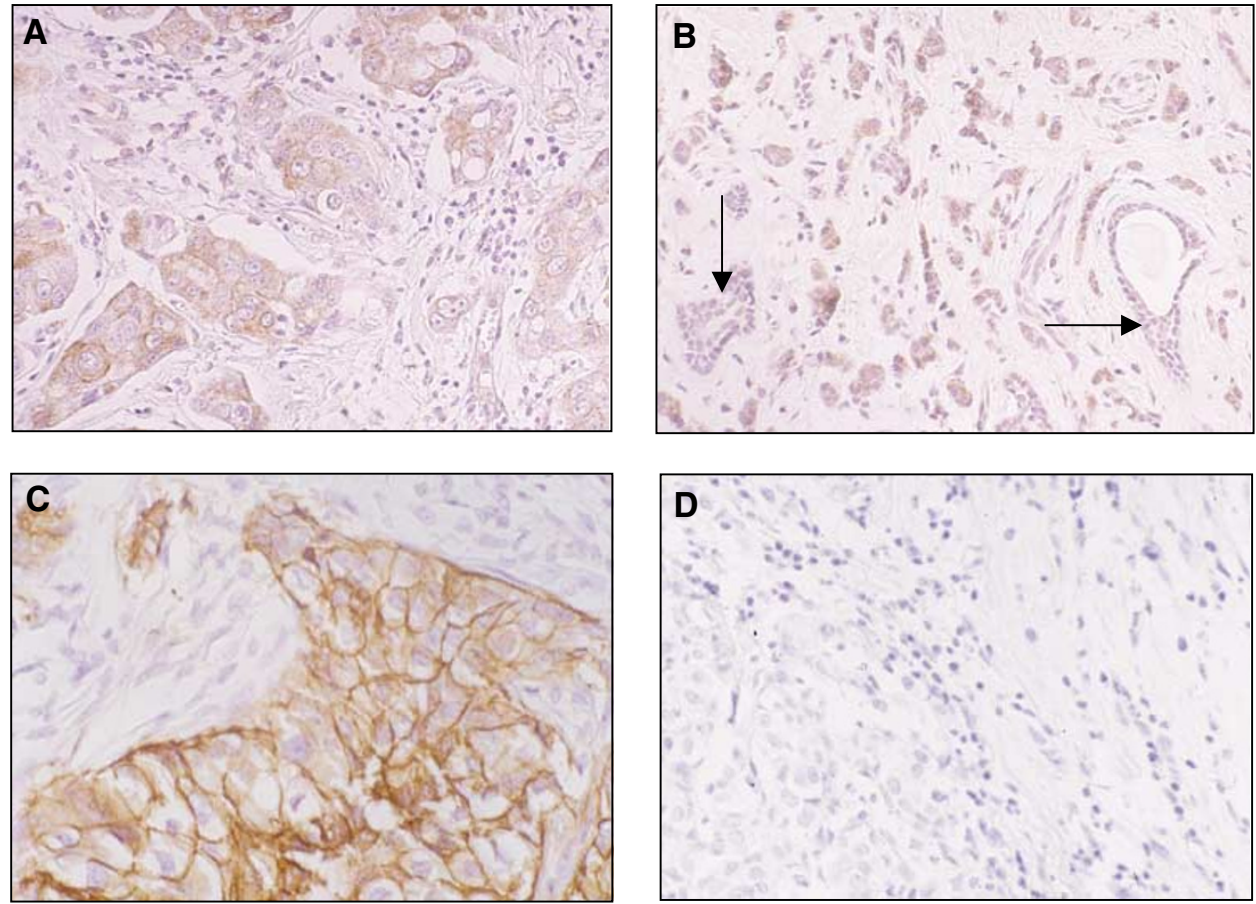

Figure I (A) Example of an invasive ductal carcinoma with strong cytoplasmic COX-2 staining, classified as tumour with COX-2 overexpression. (B) Tumour sample showing COX-2 overexpression in invasive lobular carcinoma surrounding normal epithelium lacking COX-2 expression (arrows) as internal negative control. (C) Example of invasive ductal carcinoma presenting with strong membraneous Ep-CAM staining, classified as tumour with EpCAM overexpression. (D) Invasive ductal carcinoma without Ep-CAM expression as negative control. 
COX-2 and Ep-CAM overexpression and established prognostic markers, these variables were subjected to multivariate analysis (Cox regression).

\section{RESULTS}

In normal mammary epithelium COX-2 showed absent to weak staining (Figure 1B). COX-2 overexpression in tumour tissue (Figure 1A) was found in 103 of $212(48.6 \%)$ tumour specimens and correlated with poor disease-free $(P=0.02$, Figure $2 \mathrm{~A})$ and overall survival $(P=0.04$, Figure $2 \mathrm{~B})$. Remarkably, COX-2 overexpression was significantly correlated with Ep-CAM overexpression $\left(P<0.009 ; \chi^{2}\right.$ test $)$, histologic tumour type $(P=0.011)$ and menopausal status $(p=0.047)$ but failed to correlate with Her-2/ neu status or other tumour parameters (Table 1). In $46(21.7 \%)$ of the tumour specimens overexpression of both COX-2 and Ep-CAM was found, while 79 (37.3\%) showed neither COX-2 nor Ep-CAM overexpression. Further, three distinct subgroups were identified by the expression of COX-2 and Ep-CAM antigens (Figure 3A, B). Patients with tumours overexpressing both antigens carried the poorest prognosis. Median disease-free and median overall survival time in this patient population were 55 months and 90 months, respectively. Patients overexpressing either COX-2 or EpCAM had an intermediate prognosis with a median time to relapse of 127 months and a median survival time of 147 months. Finally, patients without overexpression of COX-2 and Ep-CAM in their tumours carried the best prognosis. Median time to relapse and
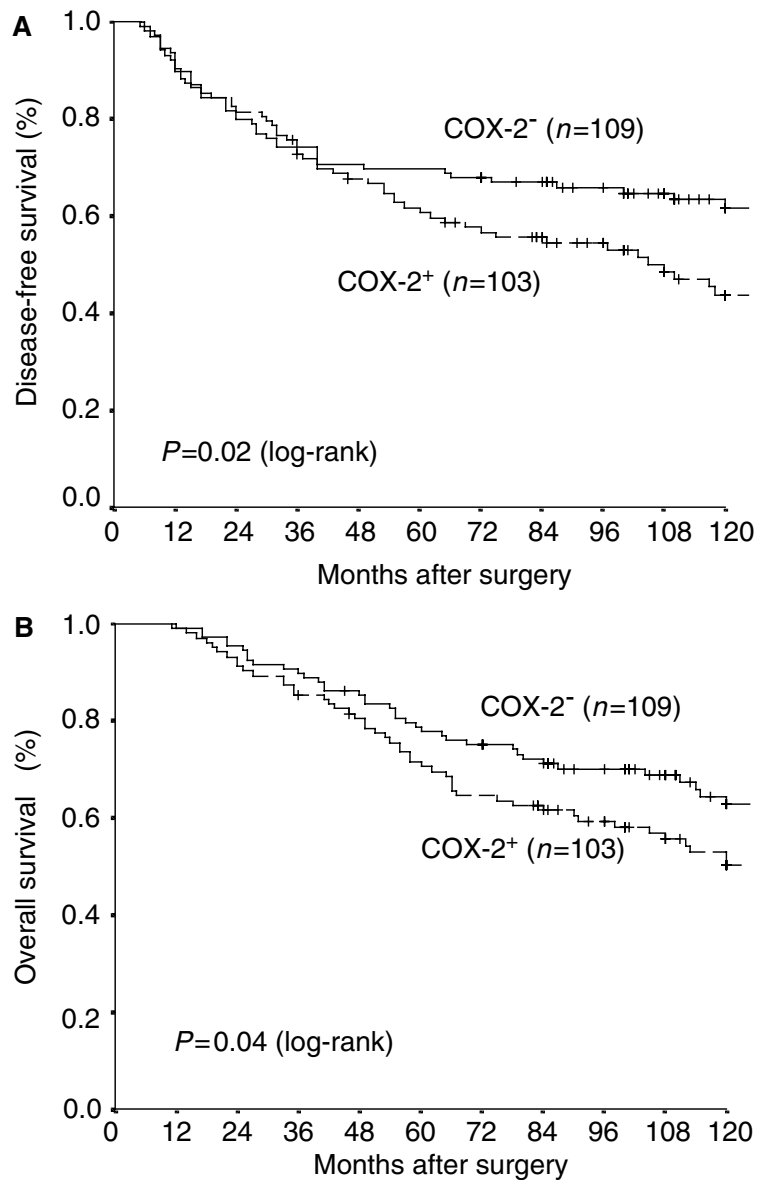

Figure 2 COX-2 overexpression as prognostic marker in a patient sample of 212 breast cancer patients. Patients with tumour tissue presenting COX-2 overexpression $\left(\mathrm{COX}-2^{+}\right)$had a significant shortened disease-free intervall (A) and overall survival (B) as compared to patients with tumours lacking $\mathrm{COX}-2$ overexpression $\left(\mathrm{COX}-2^{-}\right)$.
Table I Relationship of COX-2 overexpression and conventional clinical and tumour parameters

\begin{tabular}{|c|c|c|c|c|c|c|}
\hline \multirow[b]{2}{*}{ Characteristics } & \multirow{2}{*}{$\begin{array}{c}\text { Patients } \\
\text { no. }\end{array}$} & \multicolumn{2}{|c|}{ No } & \multicolumn{2}{|c|}{ Yes } & \multirow[b]{2}{*}{$P$-value ${ }^{\text {a }}$} \\
\hline & & no. & $\%$ & no. & $\%$ & \\
\hline \multicolumn{7}{|l|}{ Age at diagnosis } \\
\hline$<50$ & 93 & 55 & 59 & 38 & 41 & 0.047 \\
\hline$\geqslant 50$ & 119 & 54 & 45 & 65 & 55 & \\
\hline \multicolumn{7}{|l|}{ Histological type } \\
\hline Ductal & 148 & 71 & 48 & 77 & 52 & 0.011 \\
\hline Lobular & 45 & 22 & 49 & 23 & 51 & \\
\hline Other types & 19 & 16 & 84 & 3 & 16 & \\
\hline \multicolumn{7}{|l|}{ Histologic grade } \\
\hline 1 00 & 11 & 8 & 73 & 3 & 27 & 0.291 \\
\hline$\|$ & 129 & 62 & 48 & 67 & 52 & \\
\hline III & 66 & 33 & 50 & 33 & 50 & \\
\hline $\mathrm{NE}$ & 6 & & & & & \\
\hline \multicolumn{7}{|l|}{ Nodal status } \\
\hline pNO & 100 & 51 & 51 & 49 & 49 & 0.909 \\
\hline $\mathrm{pNI} / 2 / 3$ & 112 & 58 & 52 & 54 & 48 & \\
\hline \multicolumn{7}{|l|}{ Tumour size $(\mathrm{cm})$} \\
\hline$<2$ & 83 & 44 & 53 & 39 & 47 & 0.214 \\
\hline $2-5$ & 99 & 50 & 51 & 49 & 49 & \\
\hline$>5$ & 9 & 2 & 22 & 7 & 78 & \\
\hline Unknown ${ }^{\mathrm{b}}$ & 21 & & & & & \\
\hline \multicolumn{7}{|l|}{ ER } \\
\hline Neg: 0-9 fmol & 45 & 20 & 44 & 25 & 56 & 0.367 \\
\hline Pos: >9 mol & 136 & 71 & 52 & 65 & 48 & \\
\hline Unknown ${ }^{b}$ & 31 & & & & & \\
\hline \multicolumn{7}{|l|}{$P R$} \\
\hline Neg: 0-9 fmol & 62 & 26 & 42 & 36 & 58 & 0.105 \\
\hline Pos: >9 fmol & 119 & 65 & 55 & 54 & 45 & \\
\hline Unknown ${ }^{b}$ & 31 & & & & & \\
\hline \multicolumn{7}{|l|}{ Her-2/neu } \\
\hline Pos & 52 & 22 & 42 & 30 & 58 & 0.130 \\
\hline Neg & 160 & 87 & 54 & 73 & 46 & \\
\hline \multicolumn{7}{|l|}{ Ep-CAM } \\
\hline Pos & 76 & 30 & 39 & 46 & 61 & 0.009 \\
\hline $\mathrm{Neg}$ & 136 & 79 & 58 & 57 & 42 & \\
\hline
\end{tabular}

${ }^{a} \chi^{2}$ test. ${ }^{b}$ Unknown cases are excluded from $P$-value calculation. $N E=$ not evaluable. COX-2 overexpression was significantly correlated with Ep-CAM overexpression, histologic tumour type and menopausal status, but failed to correlate with other tumour parameters.

median survival time for this patient group were not reached. By subgroup analysis, overexpression of COX-2 in node-positive cases predicted a dismal prognosis regarding disease-free and overall survival, whereas in node-negative cases COX-2 overexpression was of no prognostic value (data not shown). By multivariate analysis, nodal status, Ep-CAM overexpression, tumour size and histologic grade, but not COX-2 overexpression, proved to be independent prognostic variables for overall survival. For diseasefree survival, nodal status, tumour size and Ep-CAM overexpression, but not COX-2 overexpression, were independent prognostic factors (Table 2).

\section{DISCUSSION}

Our study on 212 patients with invasive breast cancer confirms previous reports that COX-2 overexpression is rather frequent in 
Table 2 Multivariate analysis of various prognostic markers including Ep-CAM and COX-2 overexpression

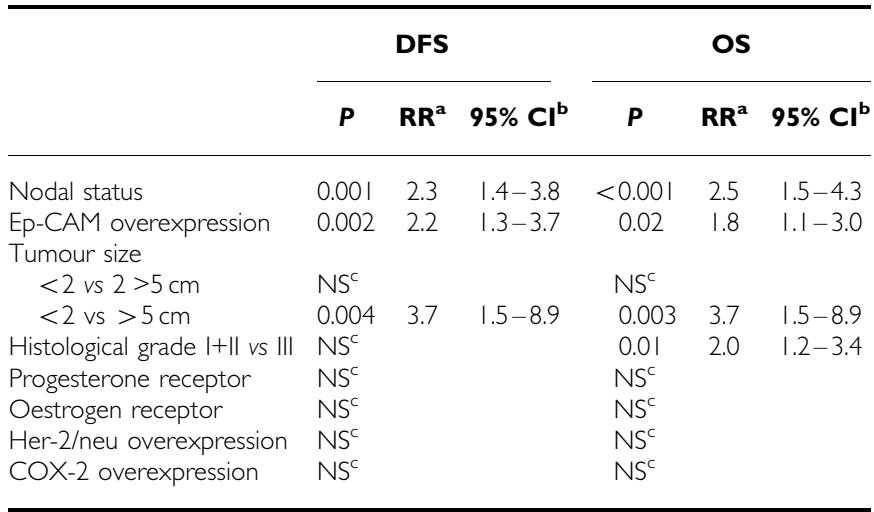

${ }^{a}$ Relative risk. ${ }^{b}$ Confidence interval. ${ }^{\mathrm{c}}$ Not significant.

this patient population (Soslow et al, 2000) and predicts a dismal prognosis for breast cancer patients (Ristimaki et al, 2002).

In experimental studies, COX-2 expression was related to local tumour invasiveness and metastatic potential (Tsujii et al, 1997). It has recently been demonstrated that COX-2 enhances angiogenesis, an effect that can be blocked by selective COX-2 inhibitors (Masferrer et al, 2000). Thus, COX-2 overexpression may provide a clinically useful biomarker for estimating tumour aggressiveness and patients' prognosis.

In our series, COX-2 overexpression was found to be absent in normal mammary gland epithelium surrounding malignant tissue. This observation is in keeping with recent data showing frequently higher COX-2 expression in various epithelial neoplasia compared with adjacent normal tissue (Soslow et al, 2000; Ristimaki et al, 2002).

Ep-CAM expression was found to correlate with cell proliferation and dedifferentiation in epithelial cells (de Boer et al, 1999). To date, little is known about the molecular mechanisms responsible for the regulation of the Ep-CAM gene. The highly significant association of COX-2 and Ep-CAM overexpression suggests a linkage between COX-2 and Ep-CAM signalling. Indeed, Tsujii and DuBois (1995) demonstrated that COX-2 can disrupt cell adhesion mediated by cadherins. Downregulation of cadherins in turn can upregulate Ep-CAM expression. Moreover, cytokines such as IFN $\alpha$ have been shown to upregulate both COX-2 and EpCAM expression in epithelial tumour cells (Bostrom et al, 2001; Flieger et al, 2001). Notably, no correlation was found between Her-2/neu and COX-2 overexpression. This finding is somewhat unexpected, since at least in colorectal cells, COX-2 can be upregulated by Her-2/neu receptor signalling (Vadlamudi et al, 1999). Taken together, upon validation in prospective studies, the combination of COX-2 and Ep-CAM expression may significantly improve the estimation of breast cancer prognosis. Beside this,

\section{REFERENCES}

Bennett A, Charlier EM, McDonald AM, Simpson JS, Stamford IF, Zebro T (1977) Prostaglandins and breast cancer. Lancet 2: 624-626

Bostrom PJ, Uotila P, Rajala P, Nurmi M, Huhtaniemi I, Laato M (2001) Interferon-alpha inhibits cyclooxygenase-1 and stimulates cyclooxygenase- 2 expression in bladder cancer cells in vitro. Urol Res 29: $20-24$

Chan G, Boyle JO, Yang EK, Zhang F, Sacks PG, Shah JP, Edelstein D, Soslow RA, Koki AT, Woerner BM, Masferrer JL, Dannenberg AJ (1999) Cyclooxygenase-2 expression is up-regulated in squamous cell carcinoma of the head and neck. Cancer Res 59: 991 -994
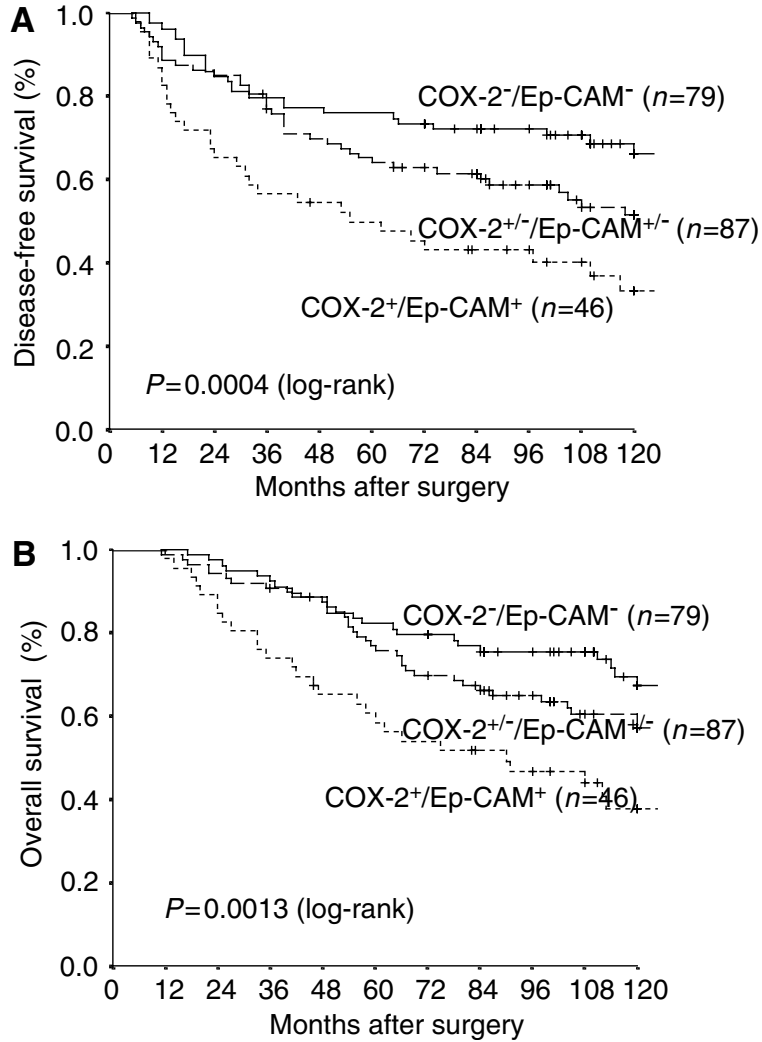

Figure 3 Relationship between COX-2 and Ep-CAM overexpression with disease-free survival $(\mathbf{A})$ and overall survival (B). COX-2 ${ }^{+} / \mathrm{Ep}-\mathrm{CAM}^{+}$: patients with tumours overexpressing both antigens, with a median diseasefree and overall survival of 55 and 90 months, respectively. COX-2 $2^{+/-} /$Ep$\mathrm{CAM}^{+/-}$: patients with tumours overexpressing only one of the two antigens, with a median disease-free and overall survival of I27 and I47 months, respectively. COX- $2^{-} / \mathrm{Ep}-\mathrm{CAM}^{-}$: patients with tumours without overexpression of the antigens, where median disease-free and overall survival were not reached.

COX-2 and Ep-CAM expression have come into focus as novel targets for therapeutic interventions in colorectal cancer. It remains to be seen whether COX-2 inhibitors and Ep-CAM directed monoclonal antibodies turn out to be efficacious for the treatment of other epithelial cancers such as breast carcinoma.

\section{ACKNOWLEDGEMENT}

We thank Ms Ines Tschörner (Institute of Pathology) for her excellent technical assistance. de Boer CJ, van Krieken JH, Janssen-van Rhijn CM, Litvinov SV (1999) Expression of Ep-CAM in normal, regenerating, metaplastic, and neoplastic liver. J Pathol 188: 201-206

Flieger D, Hoff AS, Sauerbruch T, Schmidt-Wolf IG (2001) Influence of cytokines, monoclonal antibodies and chemotherapeutic drugs on epithelial cell adhesion molecule (EpCAM) and LewisY antigen expression. Clin Exp Immunol 123: 9-14

Gastl G, Spizzo G, Obrist P, Dunser M, Mikuz G (2000) Ep-CAM overexpression in breast cancer as a predictor of survival. Lancet 356: $1981-1982$ 
Gately S (2000) The contributions of cyclooxygenase-2 to tumor angiogenesis. Cancer Metast Rev 19: 19-27

Gottlinger HG, Funke I, Johnson JP, Gokel JM, Riethmuller G (1986) The epithelial cell surface antigen 17-1A, a target for antibody-mediated tumor therapy: its biochemical nature, tissue distribution and recognition by different monoclonal antibodies. Int J Cancer 38: 47-53

Hwang D, Scollard D, Byrne J, Levine E (1998) Expression of cyclooxygenase-1 and cyclooxygenase-2 in human breast cancer. J Natl Cancer Inst 90: $455-460$

Khuri FR, Wu H, Lee JJ, Kemp BL, Lotan R, Lippman SM, Feng L, Hong WK, Xu XC (2001) Cyclooxygenase-2 overexpression is a marker of poor prognosis in stage I non-small cell lung cancer. Clin Cancer Res 7: 861 867

Kokawa A, Kondo H, Gotoda T, Ono H, Saito D, Nakadaira S, Kosuge T, Yoshida S (2001) Increased expression of cyclooxygenase-2 in human pancreatic neoplasms and potential for chemoprevention by cyclooxygenase inhibitors. Cancer 91: 333-338

Litvinov SV, Velders MP, Bakker HA, Fleuren GJ, Warnaar SO (1994) EpCAM: a human epithelial antigen is a homophilic cell-cell adhesion molecule. J Cell Biol 125: 437-446

Liu CH, Chang SH, Narko K, Trifan OC, Wu MT, Smith E, Haudenschild C, Lane TF, Hla T (2001) Overexpression of cyclooxygenase-2 is sufficient to induce tumorigenesis in transgenic mice. J Biol Chem 276: $18563-$ 18569

Liu XH, Rose DP (1996) Differential expression and regulation of cyclooxygenase-1 and -2 in two human breast cancer cell lines. Cancer Res 56: $5125-5127$

Masferrer JL, Leahy KM, Koki AT, Zweifel BS, Settle SL, Woerner BM, Edwards DA, Flickinger AG, Moore RJ, Seibert K (2000) Antiangiogenic and antitumor activities of cyclooxygenase-2 inhibitors. Cancer Res 60: $1306-1311$

Molina MA, Sitja-Arnau M, Lemoine MG, Frazier ML, Sinicrope FA (1999) Increased cyclooxygenase- 2 expression in human pancreatic carcinomas and cell lines: growth inhibition by nonsteroidal anti-inflammatory drugs. Cancer Res 59: $4356-4362$

Okami J, Yamamoto H, Fujiwara Y, Tsujie M, Kondo M, Noura S, Oshima S, Nagano H, Dono K, Umeshita K, Ishikawa O, Sakon M, Matsuura N, Nakamori S, Monden M (1999) Overexpression of cyclooxygenase-2 in carcinoma of the pancreas. Clin Cancer Res 5: 2018-2024

Riethmuller G, Holz E, Schlimok G, Schmiegel W, Raab R, Hoffken K, Gruber R, Funke I, Pichlmaier H, Hirche H, Buggisch P, Witte J,
Pichlmayr R (1998) Monoclonal antibody therapy for resected Dukes' C colorectal cancer: seven-year outcome of a multicenter randomized trial. J Clin Oncol 16: $1788-1794$

Ristimaki A, Sivula A, Lundin J, Lundin M, Salminen T, Haglund C, Joensuu H, Isola J (2002) Prognostic significance of elevated cyclooxygenase-2 expression in breast cancer. Cancer Res 62: 632-635

Rolland PH, Martin PM, Jacquemier J, Rolland AM, Toga M (1980) Prostaglandin in human breast cancer: evidence suggesting that an elevated prostaglandin production is a marker of high metastatic potential for neoplastic cells. J Natl Cancer Inst 64: 1061 - 1070

Sheng H, Shao J, Morrow JD, Beauchamp RD, DuBois RN (1998) Modulation of apoptosis and Bcl-2 expression by prostaglandin E2 in human colon cancer cells. Cancer Res 58: $362-366$

Shono T, Tofilon PJ, Bruner JM, Owolabi O, Lang FF (2001) Cyclooxygenase-2 expression in human gliomas: prognostic significance and molecular correlations. Cancer Res 61: 4375-4381

Soslow RA, Dannenberg AJ, Rush D, Woerner BM, Khan KN, Masferrer J, Koki AT (2000) COX-2 is expressed in human pulmonary, colonic, and mammary tumors. Cancer 89: 2637-2645

Spizzo G, Obrist P, Ensinger C, Theurl I, Dunser M, Ramoni A, Gunsilius E, Eibl G, Mikuz G, Gastl G (2002) Prognostic significance of Ep-CAM AND Her-2/neu overexpression in invasive breast cancer. Int J Cancer 98: $883-888$

Tsujii M, DuBois RN (1995) Alterations in cellular adhesion and apoptosis in epithelial cells overexpressing prostaglandin endoperoxide synthase 2. Cell 83: 493-501

Tsujii M, Kawano S, DuBois RN (1997) Cyclooxygenase-2 expression in human colon cancer cells increases metastatic potential. Proc Natl Acad Sci USA 94: $3336-3340$

Tsujii M, Kawano S, Tsuji S, Sawaoka H, Hori M, DuBois RN (1998) Cyclooxygenase regulates angiogenesis induced by colon cancer cells. Cell 93: 705-716

Vadlamudi R, Mandal M, Adam L, Steinbach G, Mendelsohn J, Kumar R (1999) Regulation of cyclooxygenase-2 pathway by HER2 receptor. Oncogene 18: 305-314

Yoshimura R, Sano H, Masuda C, Kawamura M, Tsubouchi Y, Chargui J, Yoshimura N, Hla T, Wada S (2000) Expression of cyclooxygenase-2 in prostate carcinoma. Cancer 89: 589-596

Zimmermann KC, Sarbia M, Weber AA, Borchard F, Gabbert HE, Schror K (1999) Cyclooxygenase-2 expression in human esophageal carcinoma. Cancer Res 59: 198-204 